\title{
Acute Pain after Thoracic Surgery Predicts Long-Term Post-Thoracotomy Pain
}

\author{
* $¥$ Joel Katz, Ph.D., *Marla Jackson, B.A., $† \$ B r i a n$ P. Kavanagh, M.B., and \\ †Alan N. Sandler, M.B. \\ Departments of *Psychology and tAnaesthesia, The Toronto Hospital, and Departments of $¥$ Behavioural Science and \\ \$Anaesthesia, University of Toronto, Toronto, Ontario, Canada
}

\begin{abstract}
:
Objective: Long-term pain is a common sequela of thoracotomy, occurring in approximately $50 \%$ of patients 2 years after thoracic surgery. Despite this alarming statistic, little is known about the factors responsible for the transition of acute to chronic pain. The aim of the present study is to identify predictors of long-term post-thoracotomy pain.

Design: Follow-up was for 1.5 years for patients who had participated in a prospective, randomized, controlled trial of preemptive, multimodal analgesia.

Setting: Subjects were recruited from a tertiary care center.

Pattents: Thirty patients who had undergone lateral thoracotomy were followed up by telephone, administered a structured interview, and classified according to long-term pain status.

Main Outcome Measures: Present pain status was measured by a verbal rating scale (VAS). Measures obtained within the first $48 \mathrm{~h}$ after surgery were compared between patients with and without pain 1.5 years later. These include VAS pain scores at rest and after movement, McGill Pain Questionnaire data, patient-controlled morphine consumption (mg), and pain thresholds to pressure applied to a rib contralateral to the thoracotomy incision.

Regults: Fifty-two percent of patients reported long-term pain. Early postoperative pain was the only factor that significantly predicted long-term pain. Pain intensity $24 \mathrm{~h}$ after surgery, at rest, and after movement was significantly greater among patients who developed long-term pain compared with pain-free patients. A significant predictive relationship was also found at 24 and $48 \mathrm{~h}$ using the McGill Pain Questionnaire. Cumulative morphine was comparable for the two groups. Pain thresholds to pressure applied to a rib contralateral to the incision did not differ significantly between the groups.

Conclusion: Aggressive management of early postoperative pain may reduce the likelihood of long-term post-thoracotomy pain.
\end{abstract}

Key Words: Thoracotomy-Long-term pain-McGill Pain Questionnaire.

Post-thoracotomy pain syndrome is defined as an aching or burning pain that persists or recurs along a thoracotomy scar at least 2 months after surgery (1). It is estimated that half of all patients still alive

Address correspondence and reprint requests to Dr. J. Katz, Ph.D., Department of Psychology, The Toronto Hospital (General Division), 200 Elizabeth Street, CW 2-306, Toronto, Ontario, Canada MSG 2C4.
1-2 years after thoracotomy will suffer with persistent chest wall pain (2). Despite this alarming rate, very little is known about the factors that mark the transition from time-limited pain to chronic, pathological pain.

Recent progress in the area of acute pain mechanisms suggests that high-intensity, noxious stimulation sufficient to activate $C$-fiber afferents may set the stage for long-term pain. Experimental models of neuropathic pain show that while both peripheral 
and central nervous system (CNS) mechanisms play significant roles in initiating nociceptive behavior, altered CNS processing appears to be responsible for its maintenance (3-5). Clinical evidence that CNS plasticity contributes to persistent pain comes from studies of amputees who complain of phantom limb pain that resembles a painful preamputation lesion $(6,7)$. Additional evidence indicates that male neonatal circumcision is associated with a greater response to vaccination several months later (8). Conversely, blocking the afferent barrage induced by surgical incision and other noxious perioperative events reduces postoperative pain intensity $(3,9)$. Preincisional epidural administration of an opioid (10) or local anaesthetic (11) and preincisional i.v. administration of morphine (12) are more effective in reducing postoperative pain and/or analgesic requirements than postincisional administration of the same agent by the same route. Taken together, these studies suggest that traumatic peripheral injuries trigger long-lasting changes in the CNS which may underlie the transition from acute to chronic pain $(13,14)$.

The aim of the present study was to evaluate the relationship between early postoperative pain and long-term post-thoracotomy pain. Patients who participated in a prospective, randomized study (15) comparing preemptive multimodal analgesia with a placebo control condition were contacted approximately 1.5 years after thoracotomy and interviewed about the presence or absence of long-term pain. In the original study (15), use of preemptive multimodal analgesia during surgery was not found to be more effective than the placebo in reducing the intensity of acute postoperative pain. Notwithstanding these negative findings, we were interested in evaluating the relationship between early postoperative pain intensity and long-term post-thoracotomy pain. We hypothesized that acute postoperative pain intensity would predict long-term post-thoracotomy pain.

\section{METHODS}

The study was approved by The Toronto Hospital Committee for Research on Human Subjects. Written informed consent was obtained from all patients. Baseline preoperative Beck Depression Inventory (BDI; 16) and Spielberger (17) state (STAI-S) and trait (STAI-T) anxiety assessments were completed the day before surgery. Pre- and postoperative pain thresholds to pressure were as- sessed in $\mathrm{lb} / \mathrm{in}^{2}$ (PSI) using an algometer (Pressure Threshold Meter; Pain Diagnostics and Thermography, Great Neck, NY, U.S.A.) on the skin overlying the lateral aspect of the fifth or sixth rib contralateral to the (proposed) incision.

A visual analogue scale (18) was used to assess postoperative pain intensity at rest (VAS-R) and after movement (VAS-M). Pain was also assessed with the McGill Pain Questionnaire (MPQ; 19). A patient-controlled analgesia (PCA) infusion pump (Abbott Life Care II Infuser, Chicago, IL, U.S.A.) was set to deliver a $1.5-2.0 \mathrm{mg}$ i.v. bolus dose of morphine with a lockout time of $6 \mathrm{~min}$, a maximum dose of $30 \mathrm{mg}$ in any $4 \mathrm{~h}$ period, and no background infusion. No other analgesics were provided during the $72 \mathrm{~h}$ study period.

Patients were contacted by telephone approximately 1.5 years after surgery by a research assistant who was unaware of the purpose of the study. A standardized questionnaire was administered to each patient assessing the absence or presence and intensity of pain in the region of the thoracotomy scar at rest and after movement. All patients reporting pain rated it on a 0-10 verbal rating scale (VRS). Patients were assigned to one of two groups based on the presence or absence of long-term post-thoracotomy pain.

Demographic and clinical variables were analyzed by unpaired $t$ test (parametric data) and $\chi^{2}$ test (frequency data). VAS-R, VAS-M, and MPQ scores were analyzed by the Mann-Whitney $U$ test. Pain thresholds were analyzed by two-way repeated measures analysis of covariance. Cumulative morphine consumption was analyzed by unpaired $t$ test. Correlations between demographic/clinical variables and postoperative pain were calculated by the Pearson (parametric) or Spearman (non-parametric) method using Bonferonni's type I error rate correction. The value $p<0.05$ was considered statistically significant.

\section{RESULTS}

Of the 30 patients enrolled in the study approximately 1.5 years earlier, $23(77 \%)$ were contacted and interviewed by telephone, three (I0\%) had died, and four (13\%) could not be reached. Eleven of the 23 patients (48\%) from whom follow-up information was obtained reported being pain-free. The remaining 12 patients $(52 \%)$ reported that they continued to suffer from post-thoracotomy pain on a daily or weekly basis. The typical description was 
TABLE 1. Demographic characteristics and clinical variables at the time of surgery for patients with or without pain 1.5 years later

\begin{tabular}{lcc}
\hline Characteristic/variable & $\begin{array}{c}\text { Long-term pain } \\
(\mathrm{n}=12)\end{array}$ & $\begin{array}{c}\text { Pain-free } \\
(\mathrm{n}=11)\end{array}$ \\
\hline Multimodal analgesia (n) & 7 & 6 \\
Male:Female (n) & $6: 6$ & $7: 4$ \\
Months since surgery ( $\pm \mathrm{SD})$ & $19.6(3.8)$ & $19.3(4.3)$ \\
Age at surgery $(\mathrm{yr} \pm \mathrm{SD})$ & $55(16.0)$ & $60.4(7.6)$ \\
Weight $(\mathrm{kg} \pm \mathrm{SD})$ & $68.0(8.1)$ & $75.6(13.01)$ \\
Blood loss (ml \pm SD) & $370(265)$ & $341(361)$ \\
Surgery duration (min $\pm \mathrm{SD})$ & $191(41.0)$ & $219(46.01)$ \\
Total O.R. fentanyl $(\mu \mathrm{g} \pm \mathrm{SD})$ & $228(53.7)$ & $289(111.3)$ \\
Frequency of diagnosis & & \\
$\quad$ Pulmonary neoplasm & 10 & 10 \\
$\quad$ Hiatus hernia & 2 & 1 \\
Frequency of procedure & & \\
$\quad$ Lobectomy & 11 & 7 \\
Pneumonectomy & 0 & 3 \\
Esophageal surgery & 1 & 1 \\
\hline
\end{tabular}

of a dull, aching or burning pain situated in the chest wall. Mean VRS pain intensity $( \pm S D$ ) was 3.3 $( \pm 1.6)$. Patients with or without long-term pain were similar on demographic characteristics and clinical variables (shown in Tables 1,2 ; all $\mathrm{p}>0.05$, $t$ test or $\chi^{2}$ ).

Early postoperative pain was the only factor that significantly predicted long-term pain. Pain intensity on the first day after surgery, both at rest (Fig. 1A) and after movement (Fig. 1B), was significantly greater among patients who developed long-term pain compared with those who did not (all $p<0.03$, Mann-Whitney $U$ test). A significant predictive relationship was also found for pain on postoperative days 1 and 2 as measured by the MPQ (Table 3). In addition, a greater proportion of patients who subsequently developed long-term pain endorsed more MPQ adjectives on days 1-3 after surgery than did pain-free patients (Table 4). Cumulative morphine consumption (Fig. 2) was virtually identical for the two groups ( $p>0.05, t$ test), indicating that the differences in pain were not mediated by postoperative analgesic usage.

TABLE 2. Mean preoperative depression and anxiety scores ( $\pm S D)$ for patients with or without pain 1.5 years after surgery

\begin{tabular}{lcc}
\hline Variable $^{a}$ & Long-term pain & Pain-free \\
\hline BDI & $5.6(4.8)$ & $8.3(4.6)$ \\
STAI-S & $44.3(6.8)$ & $37.1(9.8)$ \\
STAI-T & $36.3(10.0)$ & $39.6(10.5)$ \\
\hline
\end{tabular}

a BDI, Beck Depression Inventory; STAI-S and STAI-T Spielberger state and trait anxiety assessments, respectively.

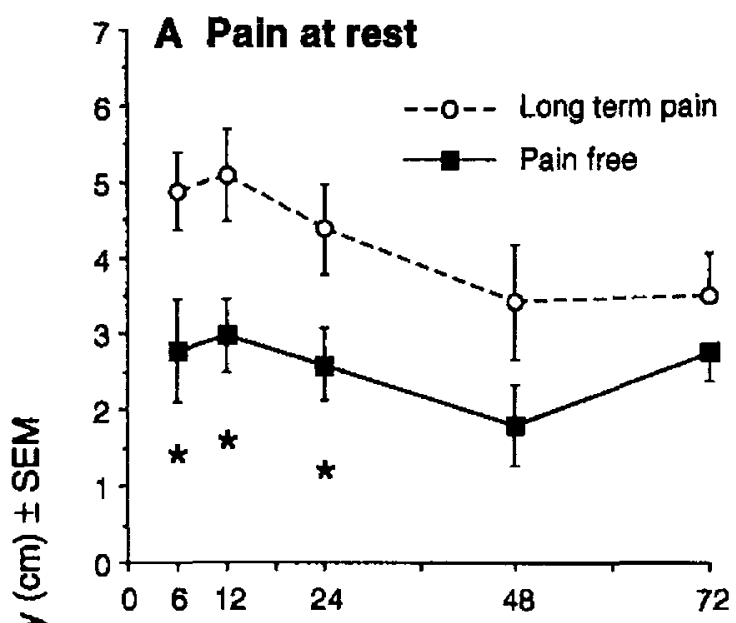

B Pain on movement

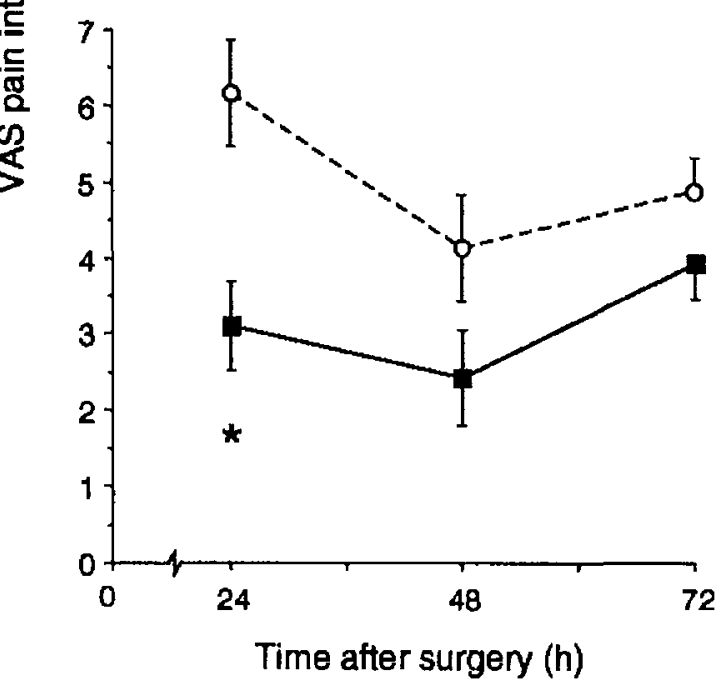

FiG. 1. Visual analogue pain scores at rest (A) and after movement (B) on postoperative days $1-3$ shown for patients with and without long-term post-thoracotomy pain. " $p<0.03$.

Scores on the BDI, STA1-S, and STAI-T were comparable for the two groups (all $\mathrm{p}>0.05, t$ test), suggesting that these psychological factors did not differentially influence the experience or reporting

TABLE 3. Total pain rating index (PRI-T) from McGill Pain Questionnaire ( $\pm S D$ ) on post-operative days $I-3$ for patients with or without pain 1.5 years after surgery

\begin{tabular}{lcc}
\hline PRI-T & Long-term pain & Pain-free \\
\hline $24 \mathrm{~h}$ & $28.0^{a}(11.4)$ & $14.4(8.7)$ \\
$48 \mathrm{~h}$ & $23.1^{a}(6.7)$ & $9.3(9.0)$ \\
$72 \mathrm{~h}$ & $23.6(12.7)$ & $15.2(13.0)$ \\
\hline
\end{tabular}

a Significantly different from the pain-free group by MannWhitney $U$ test $(p<0.007)$. 
TABLE 4. McGill Pain Questionnaire (MPQ) descriptors chosen by more than one-third of patients in the two groups

\begin{tabular}{|c|c|c|c|c|}
\hline $\begin{array}{l}\text { Time } \\
\text { (h) }\end{array}$ & $\begin{array}{l}\text { MPQ } \\
\text { class }\end{array}$ & $\begin{array}{c}\text { MPQ } \\
\text { descriptor }\end{array}$ & $\begin{array}{l}\text { Long-term pain } \\
\qquad(\%)\end{array}$ & $\begin{array}{c}\text { Pain-free } \\
(\%)\end{array}$ \\
\hline \multirow[t]{10}{*}{24} & Sensory & Stabbing & 42 & - \\
\hline & & Hot & 50 & - \\
\hline & & Sore & - & 40 \\
\hline & & Tender & 50 & 60 \\
\hline & Affective & Tiring & 67 & 70 \\
\hline & & Sickening & 58 & - \\
\hline & & Fearful & 50 & - \\
\hline & Evaluative & Annoying & 42 & - \\
\hline & Miscellaneous & Tight & 42 & - \\
\hline & & Nagging & 42 & - \\
\hline \multirow[t]{11}{*}{48} & Sensory & Sharp & 44 & 38 \\
\hline & & Pinching & 56 & - \\
\hline & & Wrenching & 44 & - \\
\hline & & Tingling & 44 & - \\
\hline & & Itchy & 44 & 38 \\
\hline & & Sore & 44 & 50 \\
\hline & & Tender & 56 & - \\
\hline & Affective & Tiring & 89 & 38 \\
\hline & Evaluative & Annoying & 67 & - \\
\hline & Miscellaneous & Penetrating & 67 & - \\
\hline & & Tight & 42 & - \\
\hline \multirow[t]{8}{*}{72} & Sensory & Sharp & 40 & - \\
\hline & & Itchy & 40 & - \\
\hline & & Aching & - & 60 \\
\hline & & Tender & 50 & - \\
\hline & Affective & Tiring & 80 & 60 \\
\hline & Miscellaneous & Tight & 40 & - \\
\hline & & Numb & - & 60 \\
\hline & & Nagging & 50 & - \\
\hline
\end{tabular}

of pain. Pre- and postoperative pain thresholds (Table 5) did not differ significantly for the two groups. Thus, the differences in postoperative pain were not due to a generalized response bias to noxious stim-

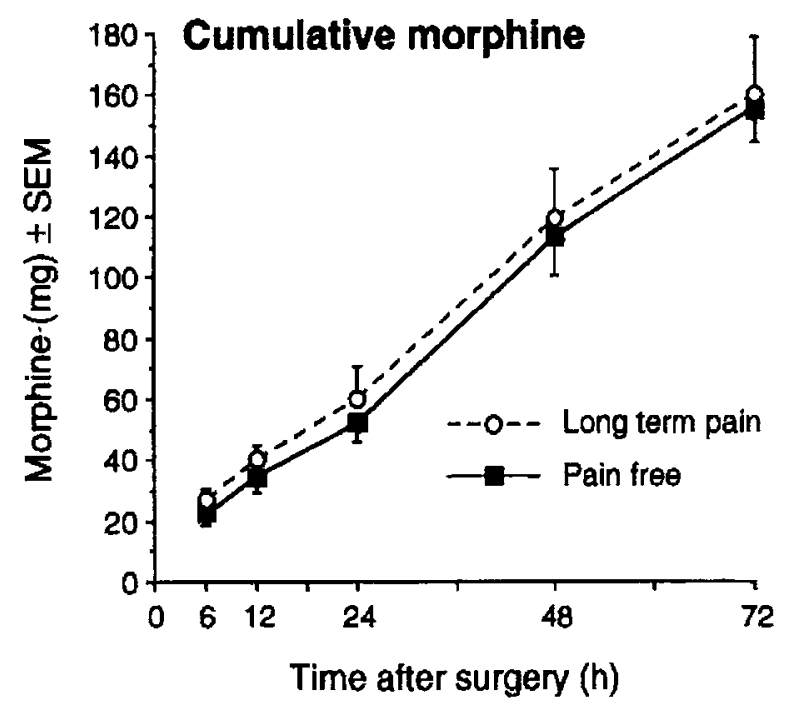

FIG. 2. Cumulative patient-controlled morphlne consumption on postoperative days $1-3$ shown for patients with and without post-thoracotomy pain 1.5 years after surgery. ulation since pain thresholds to pressure were similar when postoperative pain intensity differed. Pain did not correlate significantly with any demographic or clinical variable.

\section{DISCUSSION}

This prospective study is the first to provide clear evidence of a significant predictive relationship between the intensity and quality of acute postoperative pain and the development of chronic post-thoracotomy pain. Patients who reported pain more than 1.5 years after surgery could be distinguished from their pain-free counterparts by the intensity of pain experienced as early as $6 \mathrm{~h}$, and up to 2 days, after surgery.

Acute post-thoracotomy pain arises from multiple sources, including the wound proper, disruption of

TABLE 5. Mean pre-and postoperative pain thresholds $(P S I \pm S D)$ for patients with or without pain 1.5 years after surgery

\begin{tabular}{lcc}
\hline Variable & Long-term pain & Pain-free \\
\hline Preoperative & $10.7(2.1)$ & $8.8(2.6)$ \\
24 h postoperative & $8.9(2.3)$ & $8.1(2.4)$ \\
48 h postoperative & $9.5(2.2)$ & $8.8(2.1)$ \\
\hline
\end{tabular}


ribs and intercostal nerves, inflammation of chest wall structures adjacent to the incision, incision or crushing of pulmonary parenchyma or pleura, and thoracostomy drainage tubes (20). The precise mechanisms cannot be identified, but we suspect that perioperative intercostal nerve damage (e.g., nerve crush during rib retraction or nerve constriction when suturing) is responsible for the heightened postoperative pain as well as the long-term neuropathic pain.

The finding that morphine consumption on postoperative days 1 and 2 was comparable for the groups despite significant differences in pain indicates that patients may have been titrating morphine to some effect other than pain (e.g., sedation, nausea, personal control). More importantly, it suggests that the acute postoperative pain among patients who later developed long-term pain may not have been as responsive to morphine, a finding consistent with certain other neuropathic pains (21). The key role in central nociceptive processing played by the N-methyl-D-aspartate (NMDA) excitatory amino acid receptor raises the possibility that NMDA antagonists (e.g., ketamine and dextromethorphan) may be a useful adjunct (22). Whether aggressively treating early postoperative pain (e.g., with continuous epidural local anesthesia) will diminish the likelihood of long-term pain is not known, but it is a logical first step toward identifying factors responsible for the transition of acute, physiological pain to chronic, pathological pain.

One limitation of the present study is that patients were not examined for recurrence of malignant disease. Thus, the $52 \%$ rate of occurrence of long-term post-thoracotomy pain may be an inflated estimate of the true incidence. However, this seems unlikely based on a survey of patients who were disease-free at the time of interview, which found that $54 \%$ continued to suffer from thoracotomy pain more than 2 years after surgery (2). In addition, without a physical examination at follow-up, we are not able to specify the extent to which abnormal peripheral or central neural processes contribute to the pain. Another limitation is the small sample size, notwithstanding the prospective design and high percentage of patients reached for follow-up. Generalization to the larger population of post-thoracotomy patients may be limited. In this regard, a larger prospective study would be useful in determining the relationship between acute postoperative pain intensity and the development of long-term post-thoracotomy pain.

In summary, the results of the present study show that long-term pain 1.5 years after thoracic surgery was predicted by the intensity of pain within the first day after surgery. Acute postoperative pain was significantly more intense among patients who developed long-term pain compared with pain-free patients. Intercostal nerve damage may be responsible for both the enhanced pain shortly after surgery and the long-term pain. The role of poorly controlled acute pain in the development of longterm pain requires further study. These results point to the importance of aggressively managing acute postoperative pain not only for the immediate benefit of relieving pain but possibly also to disrupt the peripheral and central neural processes responsible for the transition to chronicity.

Acknowledgment: This study was supported by a research scholarship from the Medical Research Council of Canada (MRC) and by MRC grant MT-12052 to Dr. Katz.

\section{REFERENCES}

1. Merskey H, Bogduk N, eds. Classification of chronic pain: descriptions of chronic pain syndromes and definitions of pain terms. Seattle: IASP Press, 1994:222.

2. Dajczman E, Gordon A, Kreisman H, Wolkove N. Longterm post-thoracotomy pain. Chest 1991;99:270-4.

3. Coderre TJ, Katz J, Vaccarino AL, Melzack R. Contribution of central neuroplasticity to pathological pain: review of clinical and experimental evidence. Pain 1993;52:259-85.

4. Woolf CJ, Wall PD. Morphine-sensitive and morphineinsensitive actions of $\mathrm{C}$-fibre input on the rat spinal cord. Neurosci Lett 1986;64:221-5.

5. Woolf CJ. Generation of acute pain: central mechanisms. $\mathrm{Br}$ Med Bull 1991;47:523-33.

6. Katz J, Melzack R. Pain "memories" in phantom limbs: review and clinical observations. Pain 1990;43:319-36.

7. Jensen TS, Krebs B, Nielsen J, Rasmussen P. Immediate and long-term phantom pain in amputees: incidence, clinical characteristics and relationship to pre-amputation pain. $P$ ain 1985;21:268-78.

8. Taddio A, Goldbach M, Ipp M, Stevens B, Koren G. Effect of neonatal circumcision on pain responses during vaccination in boys. Lancet 1995;345:291-2.

9. Woolf CJ, Chong MS. Preemptive analgesia-treating postoperative pain by preventing the establishment of central sensitization. Anesth Analg 1993;77:362-79.

10. Katz J, Kavanagh BP, Sandler AN, Nierenberg H, Boylan JF, Friedlander M, Shaw BF. Preemptive analgesia: clinical evidence of neuroplasticity contributing to post-operative pain. Anesthesiology 1992;77:439-46.

11. Katz J, Clairoux M, Kavanagh BP, Roger S, Nierenberg H, Redahan C, Sandler AN. PTe-emptive lumbar epidural anaesthesia reduces postoperative pain and patient-controlled morphine consumption after lower abdominal surgery. Pain 1994;59:395-403,

12. Richmond CE, Bromley LM, Woolf CJ. Preoperative morphine pre-empts postoperative pain. Lancet 1993;342:73-5. 
13. Katz J. Preop analgesia for postop pain. Lancet 1993;342: 65-6.

14. Devor M, Basbaum AI, Bennett GJ, Blumberg H, Campbell JN, Dembowsky KP, Guilbaud G, Jänig W, Koltzenbug $M$, Levine JD, Otten UH, Portenoy RK. Group report: Mechanisms of neuropathic pain following peripheral injury. In: Basbaum AI, Besson J-M, eds. Towards a new pharmacotherapy of pain. New York: John Wiley \& Sons, 1991:41740.

15. Kavanagh BP, Katz J, Sandler AN, Nierenberg $H$, Roger $S$, Boylan JF, Laws AK. Multimodal analgesia before thoracic surgery does not reduce postoperative pain. Br $J$ Anaesth 1993;73:184-9.

16. Beck AT, Ward CH, Mendelson M, Mock J, Erbough J. An inventory measuring depression. Arch Gen Psychiatry 1961; 4:561-71.

17. Spielberger CD, Gorsuch RL, Lushene RE. STAI manual for the State-Trait Anxiety Inventory. Palo Alto, CA: Consulting Psychologists Press, 1970.

18. Huskisson EC. Visual analogue scales. In: Melzack R, ed. Pain measurement and assessment. New York: Raven Press, 1983:33-7.

19. Melzack R. The McGill Pain Questionnaire: major properties and scoring methods. Pain 1975;1:277-99.

20. Kavanagh BP, Katz J, Sandler AN. Pain control after thoracic surgery: a review of current techniques. Anesthesiology 1994;81:737-59.

21. Jadad AR, Carmoll D, Glynn CJ, Moore RA, McQuay HJ. Morphine responsiveness of chronic pain: double-blind randomised crossover study with patient-controlled analgesia. Lancet 1992;339:1367-72.

22. Dickenson AH. NMDA receptor antagonists as analgesics. In: Fields HL, Liebeskind JC, eds. Pharmacological approaches to the treatment of chronic pain: new concepts and critical issues. Seattle: IASP Press, 1994:173-87. 